\title{
Initial Thrust Measurements of Marshall's Ion-ioN Thruster
}

\author{
Natalie R. Schloeder ${ }^{1}$, Tyler Scogin ${ }^{2}$, Thomas M. Liu ${ }^{3}$, and Mitchell L.R. Walker ${ }^{4}$ \\ Georgia Institute of Technology, Atlanta, GA 30332 \\ Kurt A. Polzin ${ }^{5}$ and John W. Dankanich ${ }^{6}$ \\ NASA George C. Marshall Space Flight Center, Huntsville, AL 35811
}

and

Ane Aanesland ${ }^{7}$

Laboratoire de Physique des Plasmas (LPP), CNRS-Ecole Polytechnique, 91128 Palaiseau Cedex, France

Electronegative ion thrusters are a variation of tradition gridded ion thruster technology differentiated by the production and acceleration of both positive and negative ions. Benefits of electronegative ion thrusters include the elimination of lifetime-limiting cathodes from the thruster architecture and the ability to generate appreciable thrust from both charge species. Following the continued development of electronegative ion thruster technology as exhibited by the PEGASES (Plasma Propulsion with Electronegative GASES) thruster, direct thrust measurements are required to push interest in electronegative ion thruster technology forward. For this work, direct thrust measurements of the MINT (Marshall's Ion-ioN Thruster) will be taken on a hanging pendulum thrust stand for propellant mixtures of Sulfur Hexaflouride and Argon at volumetric flow rates of 5-25 sccm at radio frequency power levels of 100-600 watts at a radio frequency of $13.56 \mathrm{MHz}$. Acceleration grid operation is operated using a square waveform bias of \pm 300 volts at a frequency of $25 \mathrm{kHz}$.

\section{Nomenclature}

$\begin{array}{ll}\alpha & =\text { Electronegativity } \\ d_{s} & =\text { Beamlet Diameter } \\ \gamma & =\text { Thrust Correction Factor } \\ I_{s p} & =\text { Specific Impulse } \\ J_{\text {ions }} & =\text { Sheath Thickness } \\ l_{e} & =\text { Grid Gap } \\ l_{g} & =\text { Adjusted Mass of Propellant Mixture } \\ M & =\text { Ion Mass Flow Rate } \\ \dot{m}_{i} & =\text { Ion Number Density } \\ n_{i} & =\text { Total Power Input } \\ P_{i n} & =\text { Volumetric Flow Rate } \\ Q & =\text { Electron/Ion Temperature } \\ T_{e, i} & =\text { Maximum Thrust } \\ T_{M A X} & \end{array}$

\footnotetext{
${ }^{1}$ Graduate Student Researcher, School of Aerospace Engineering, nschloeder3@gatech.edu, Student Member AIAA

${ }^{2}$ Graduate Student Researcher, School of Aerospace Engineering, tscogin@gatech.edu, Student Member AIAA

${ }^{3}$ Research Engineer, School of Aerospace Engineering, thomas.liu@ae.gatech.edu, Member AIAA

${ }^{4}$ Associate Professor, School of Aerospace Engineering, mitchell.walker@ae.gatech.edu, Associate Fellow AIAA

${ }^{5}$ Propulsion Research Engineer, Propulsion Research and Technology Applications Branch, Propulsion Systems Department, kurt.a.polzin@nasa.gov, Associate Fellow AIAA

${ }^{6}$ Program Manager, Technology Development and Transfer Office, john.dankanich@nasa.gov, Associate Fellow AIAA

${ }^{7}$ Researcher, CNRS - Ecole Polytechnique, ane.aanesland@lpp.polytechnique.fr, Member AIAA 